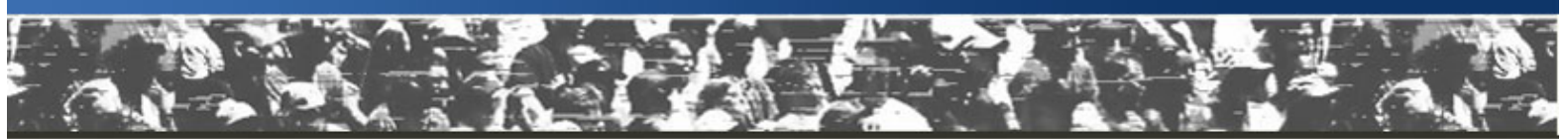

\title{
Teaching Anthropology with Museum Collections
}

\author{
Dr. Laura Peers and Dr. Giovanna Vitelli \\ University of Oxford, U.K.
}

\begin{abstract}
:
Material culture provides powerful teaching opportunities for core anthropological themes and issues. Based on experience in teaching both undergraduate and postgraduate students, the authors provide examples and a framework for a class exercise which supports students to learn from objects and to think anthropologically about them.
\end{abstract}

\section{Introduction:}

Encounters with the sensory provocations and embodied stories of material culture have the potential to ground and open up key issues of anthropological enquiry for students at all levels. Close observation of the materiality and biography of ethnographic objects provides powerful examples for considering topics central to the study of anthropology: belief systems, social and political structures, gender and age roles, economics, the embodied and sensory cultures and knowledges of everyday lives. Close observation of material culture also provides concrete references for broader thematic discussions on anthropology's history and ongoing entanglements with imperialism and colonialism; the construction of race and racism; the history of cross-cultural contacts revealed by material culture, with attendant issues of 'authenticity' and identity; and current discussions around repatriation, to give just a few examples. For anthropology students, the process of identifying and interrogating materials, textures, processes of making, and patterns of wear and use, anchors discussions of big theories and concepts, linking these to the everyday realities of lived lives.

The methodology for object analysis discussed in this article, if further integrated with collections, and with related archival and secondary source research, can create new knowledge about the object, and illuminate research in related fields which are increasingly receptive to incorporating material cultural resources (e.g. Ulrich et. al. 2015). Object encounters generate research questions which are different (and often more complex) than those stimulated by archival, textual or image databases, and enrich these other resources (Peter Miller 2013: 5). ${ }^{1}$

Object-based learning, being a collective and participatory exercise, can also highlight modalities of collaborative and Indigenous research methodologies (eg. Bohaker, Corbiere and Phillips 2014). For all of these reasons, object-based learning has been used as a pedagogical tool across the social sciences and humanities at the undergraduate and postgraduate levels for many years across North America and the UK (Vitelli 2014, 2015; Andrews et al. 2014; Chatterjee and Hannan 2015; German and Harris 2017; Duhs 2010; Riello 2017; Rose and Tolia-Kelly 2012; Woodward 2016).

Over several years of co-teaching a graduate seminar and further experiences working with undergraduate and graduate students across a range of anthropology degrees, the authors developed the exercise discussed below to introduce close object observation to anthropology students. To offer a methodologically and materially satisfactory experience to students who come from a range of specialisms and cultures, the exercise assumes no previous experience in object study. It can utilize items from any culture or historical era, and we include examples from Indigenous and European cultural contexts here 
in order to stress the transferability of the approach. The underlying premise of the exercise is that, in the process of handling objects, sensory stimulation provokes deep learning and reinforces critical thinking skills through material and intellectual close engagement. The physical stimulus to retention of the learning experience is significant: as Deborah Romanek and Bernadette Lynch observe (2008: 284), 'object-handling has a long-lasting effect and relationship with memory, more so than text-based learning...' Over many years, our students have consistently noted that sessions with material culture made anthropology real in ways that text or video did not, and were memorable long after the course.

Ideally, this exercise uses encounters with ethnographic objects in museum collections in research spaces, although it can be adapted to work with objects on display. Methodologically, it draws on techniques from a range of cognate disciplines: elements of 'close looking' adapted from literary 'close reading'; formal stylistic analysis of visual and material properties from art history; technical observation from museum conservation research; curatorial assembly of comparative items and their cultural and historical contexts; object biography and ethnographic analysis. We illustrate this process below for two objects we have used in exercises with anthropology students, together with some of the thematic considerations that were supported by information generated through close observation of the material details of the objects. This is followed by a summary of the method as it would be undertaken in a museum study room with direct physical access to the object.

\section{Unpacking objects anthropologically: examples}

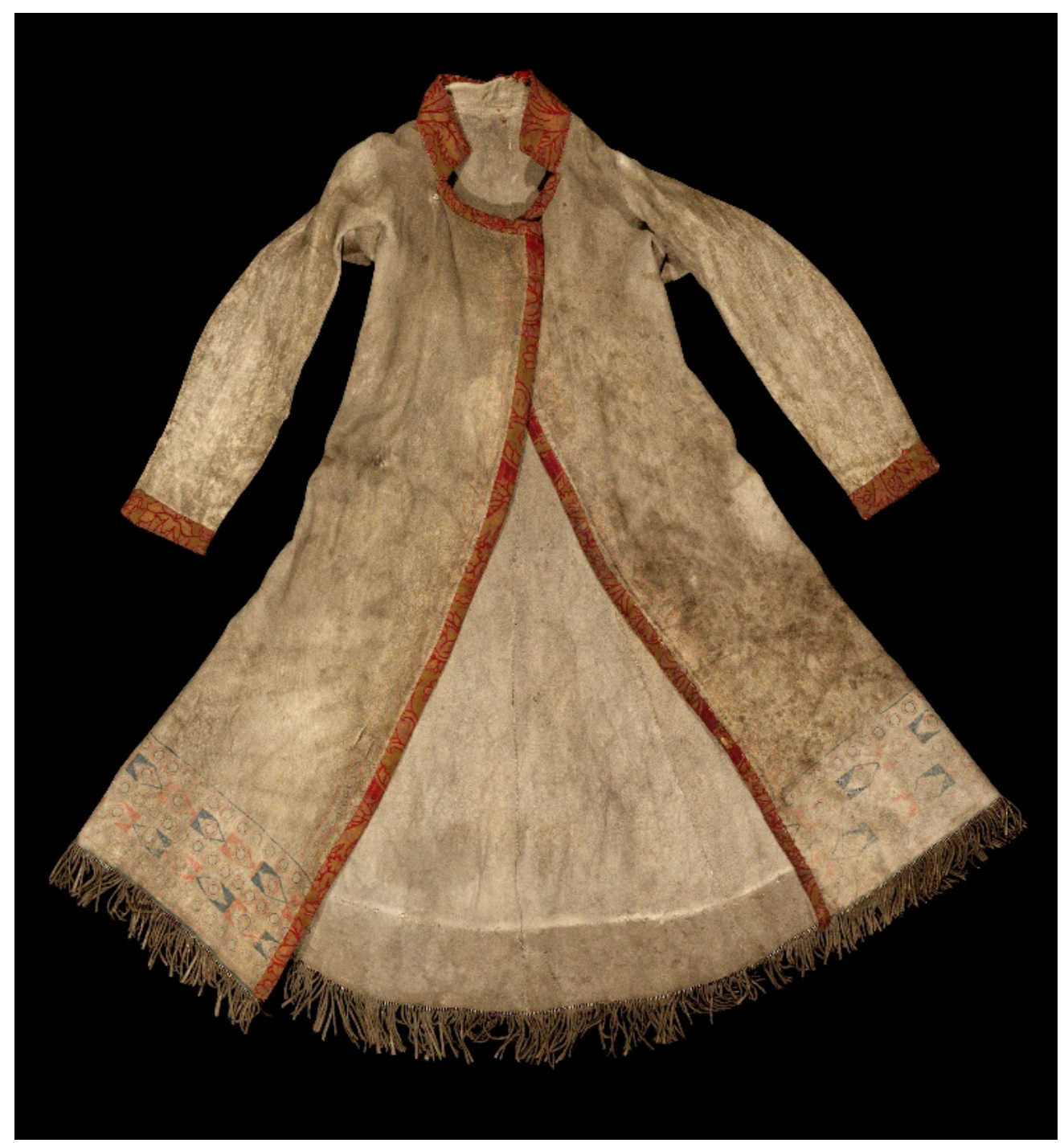

Figure 1 Hide banyan, PRM 1906.83.1. Image courtesy Pitt Rivers Museum, University of Oxford. 
The first example is a hide coat (Figure 1) at the Pitt Rivers Museum (accession number 1906.83.1). Physical and visual examination by postgraduate anthropology students (facilitated by museum staff), augmented by information in the museum catalogue record for the coat, showed that it is made of Indigenous-tanned moose or caribou hide with stamped painted decorations and dyed porcupine quill wrapping on the fringes. Students noted that it has one woven quillwork decoration across the back shoulder, and an applied wool jacquard fabric at cuffs and front facing with traces of a wool twill-weave textile lining caught in internal seams. Closer examination also revealed needle holes indicating that it formerly had a second quilled shoulder decoration, and that the jacquard facing partially covers painted designs: it was added later. Students noted that the jacquard is sewn crudely, while the original garment stitching is very even and close. Museum staff confirmed, and showed students, that all stitching is with commercial cotton or linen thread; there is no traditional sinew stitching on the garment.

Museum records contain no detailed information about the coat's origin. It was acquired from a dealer in 1906. However, searching for terms such as 'hide coat North America' in other museum databases online reveals similar examples of long hide coats with quilled and painted decoration from the Subarctic fur trade in what is now Canada. Analysis of the garment's cut also indicates that it is modelled after the banyan, a loose robe widely adopted by British men as warm, informal garments which travelled via British East India Company networks from Asian origins in the seventeenth and eighteenth centuries, as well as being influenced by early nineteenth century British men's tailoring features.

Students read contextual secondary literature placing these coats in the contexts of the northern fur trade across the subarctic and northern parklands of North America, where British men formed relationships with Indigenous women, whose linguistic and technical skills and knowledge were essential for survival and trade diplomacy (Van Kirk 1980; Racette 2005). Their children were raised either within the mother's Indigenous group, or as Métis at the post, with boys sometimes sent to Britain or Montreal for education. Educated or not, the children of these unions, and their Indigenous and Métis mothers, faced increasing racialized prejudice across the nineteenth century.

This caribou or moosehide coat is an adaptation of a wool or cotton banyan that a British Hudson's Bay Company officer took to one of the fur posts, skilfully copied and rendered into local Indigenous aesthetics and materials but retaining most of the stylistic tailored cut of the banyan. It was made by a northern Cree or Cree-Métis woman familiar with hide tanning, cutting and sewing and with porcupine quillwork decoration, who had access to commercial thread via the fur trade. After its production within this hybrid social milieu, it was brought to Britain, as many souvenirs were from the fur trade, and sent to a museum, a space where items arising from British relationships with Indigenous women were often hidden from public memory or acknowledgement. The students noted that the hide coat was catalogued as 'Indian,' rather than as the product of cross-cultural relationships across many generations which created a new people, the Métis.

Close looking at this garment thus provides a grounding and springboard for discussions about colonialism and collecting; Indigenous-white relations in colonial contexts and contexts of early modern British global expansion; race and cultural hybridity; elements of Subarctic Indigenous cultures (such as relations between humans and other-than-humans involved in hunting and hide and quill preparation, as well as gender roles, economy, and Indigenous modernities). The coat speaks to the complex realities of social relationships across cultural boundaries within which Indigenous women learned new skills, including tailoring, from British garments (and from male British tailors assigned to trading posts), and Indigenized these through the use of traditional materials and the social and spiritual relationships that harvesting those required. It speaks to the historically shifting balances of power within those crosscultural relationships and how such processes of adaptation were entangled in personal relationships between Indigenous women and British men, and through which such garments were made and given to (and also commissioned by) British men. 


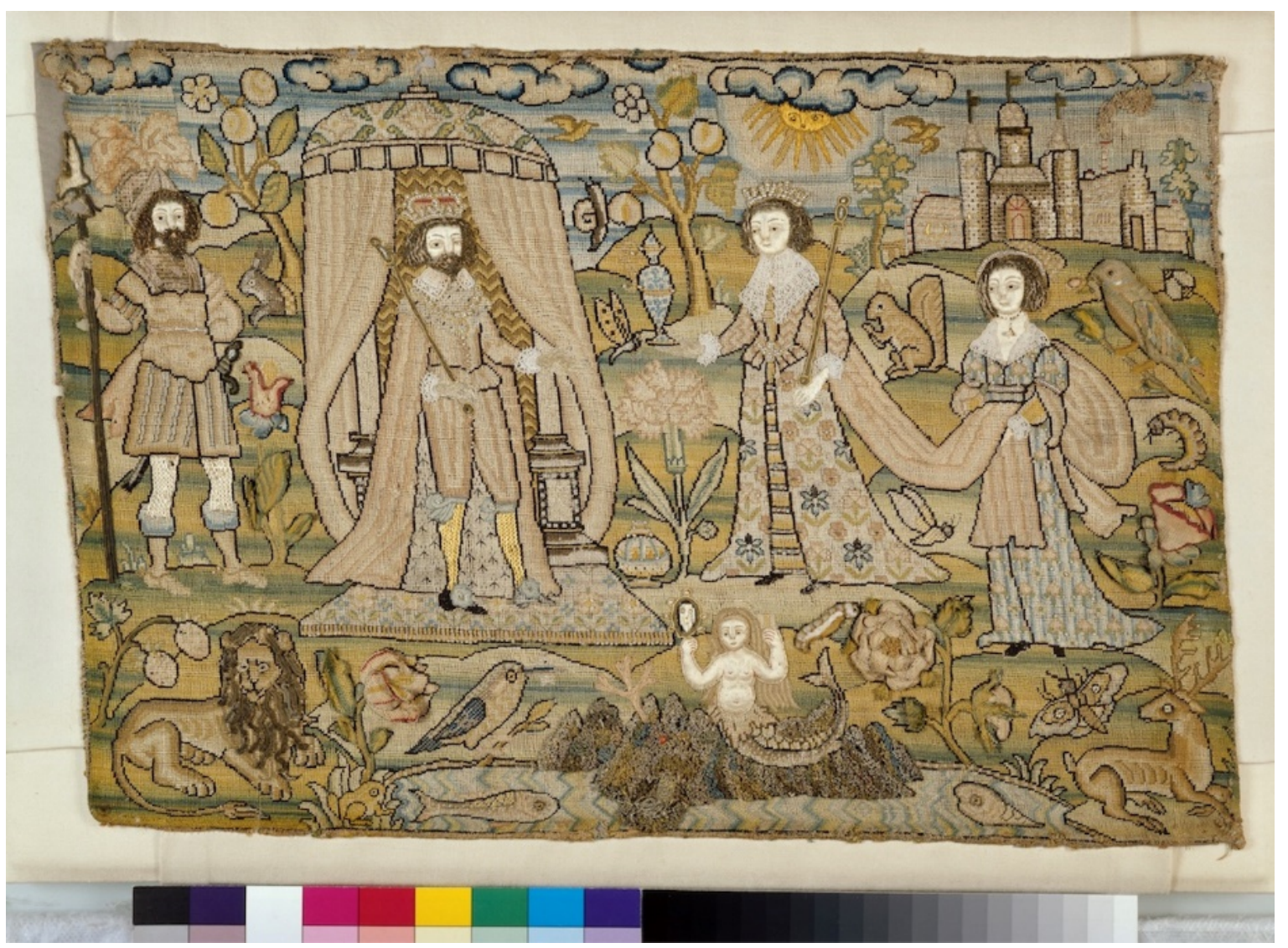

Figure 2 English seventeenth-century embroidery, ASH WA1994.142, Solomon and the Queen of Sheba. Image courtesy Ashmolean Museum, University of Oxford.

Our second example (Figure 2) illustrates how seemingly decorative Western objects can be approached through the same methodology and ethnographic perspectives. In this case, a seventeenth-century English embroidery from the Feller Collection at the Ashmolean Museum (WA1994.142) was closely studied by postgraduate anthropology students, who through their selected readings and group work were able to identify a set of anthropological themes relating to the making, using and placing of the embroidery that not only resonated with the hide coat but signposted further research questions in areas such as the social and moral place of women's craft in traditional societies and power relations between genders.

The complex pictorial panel $(31 \times 43 \mathrm{~cm})$ was made by a young woman in the second half of the seventeenth century, likely from a prosperous merchant or high-status family, during one of the most turbulent periods in English history. Social, religious and political upheaval during the English Civil Wars of the first half of the century, the execution of Charles I in 1649, the Restoration of the Stuart monarchy in 1660, and the subsequent tensions between Protestant and Catholic power structures, influenced how feminine behaviours were shaped and used to bolster authority at a time of uncertainty about inheritance, patriarchy, and power. The cultural choice of embroidery as the quintessential representation of feminine virtue was considered by students when undertaking the object analysis.

The central motif of this embroidery, as with many others, is an Old Testament biblical scene; in this case it is of Solomon receiving the Queen of Sheba. Solomon was repeatedly identified with monarchy and patriarchy. The presence of the Queen of Sheba possibly represented the ideal marriage of Wisdom and Wealth. The central themes for decorative embroideries were generally chosen by a family member or a needlework master from engravings of moral emblems or of biblical and classical scenes. The surrounding motifs of plants, animals and nature scenes were copied from pattern books, but it appears they were left to the young artist to choose; their provenance from a different source can usually be 
recognised by their out-of-scale size or style. The agency in the composition of each piece was therefore layered and complex.

This embroidery was stitched onto a plain linen backing using a mix of imported dyed silk threads, metal threads, peacock feathers, pearls and semi-precious stones. Students were able to recognise most materials and understand the skill underlying the complexity of the stitches themselves. The technically proficient piece would have been the product of extensive training at home or at boarding school in the essential gendered craft of embroidery. The investment in a young woman's training was further underlined by the considerable costs of making, and stressed the importance that a household would place on increasing the 'value' of the women: embroideries could be displayed prominently in domestic reception rooms and on articles of clothing or accessories, each item testifying to many hours spent safely working within the confines of a household and away from public gaze.

Prior to the embroidery session, participants were given short contextual readings in seventeenth-century material cultural history, chosen for their potential to link to themes connected to object study of the Pitt Rivers Indigenous material (e.g. Parker 2012; Brooks 2004; Ulrich et.al. 2015). The focus was on biblical themes of patriarchy and domestic virtue, on gendered domestic spaces, and on the sharp and disruptive contrast caused by the controversial arrival of women in the public sphere through theatre and aristocratic concubinage. Other, anthropologically-inflected readings included references to the equation of domestic virtue and moral worth with craft, the preservation of male social status through control of female behaviours, and writings on inalienable objects pertaining to women. Thus the readings covered areas both culture-specific (to give context for discussion) and anthropological (to enable connections to be made across disparate objects).

The embroidery was observed for one session and was coupled with similar examples for a second session, to emphasise how widespread the craft was among the merchant and aristocratic classes. Study sessions included close observation of the reverse of the piece (for original colour and condition, and transferred patterns), the luxury materials and the number and complexity of the stitches used. The materials and techniques were stimulus for reflection on the value accorded to the maker, the possible spaces of learning, making, using, and display, and interpretation of the chosen embroidery themes in the context of patriarchy and gender.

Object sessions with the embroidery followed the same methods as had been established with the ethnographic material. By working closely with the embroidery, as they had with the Pitt Rivers coat, students documented the embroidery's material details, its motifs and particularity. Through discussions and references to the readings, students placed the embroidery's materiality in its historic and social contexts, which in turn stimulated research questions and issues that reflected those engendered by the hide coat. For example, students hypothesised that the agency and skill in women's needle arts was valued and directly related to their identity, and that men's control of this output was both foundational and regularly subverted. Working with both the hide coat and the embroidery panel became a meaningful exercise in understanding how to create original research material irrespective of object provenance.

\section{Object encounter exercise:}

The steps below outline the method for small group encounters in a museum study room, using one or more ethnographic objects, assessing their materials and attributes and thinking outwards from those points. While this exercise does not depend on prior knowledge of specialist research methods, cultures or historic periods used as foci, it is useful to give readings for students to do before the exercise which give some cultural, historical and scholarly context for the objects. It is also helpful for the facilitator to have specialist knowledge about the items used in the exercise, to help students link observations and draw out analysis.

Step 1: Observation (5-10 minutes): Ask the students to begin by looking at the item slowly and carefully, without taking notes or photographs. The aim is to explore the object's material presence and characteristics in detail, to provide a basis for analysis, interpretation and group discussion in later steps. By moving around the object and having the object ideally available to handle and turn over, its 
unfamiliarity gradually recedes. Observe the object's surface, shape, lines, and form, including positive and negative space, colours, repetition, textures and patterns. Observe the sensory properties of the object: texture, temperature, weight, raw materials, smell, edges, patination. Examine its materials and how they are attached to each other.

Step 2: Discussion (10 minutes): Engage the students in a group discussion of observations. The aim is not to iron out differences, but to share and build a layered description of the object from multiple observational perspectives. Can the object be identified? What was it originally intended to do and who would have made and used it? Where and how was it made? What is it made of?

Step 3: Description (15 minutes): Students can work in small groups or individually to record observations, deepening their understanding of the item. Recording in different media is encouraged at this stage as part of the process of seeing more deeply: photography, video, sketching or graphed/technical drawing, or a combination to create a detailed visual diagram noting features of the object. Our students have shared data and images amongst themselves for course purposes, and also with the museums involved: museums are often grateful for additions of high-quality photographs for their own image banks. We have also shared images and data with communities of origin where we have contacts with community members.

Examples of observed detail to record could be: exactly how many fringes does it have? What are the patterns or motifs used in decoration: do they repeat, or are they modified? Are there marks of tools used to design or make it? What evidence does the object show of exposure or use? If there are damaged areas, do they reveal elements of construction? What materials are used and how might the maker have obtained the materials? (See also Andrews et.al. 2014 for questions to ask of objects at this stage.)

Step 4: Documentation and object biography: Students should review the object documentation and then discuss the object's history or biography, referring to the material details of the object as well (marks of alterations, repair, re-use). Drawing on Igor Kopytoff's (1986) notion of object biography, analysis of the life cycle of objects and their changing contexts and meanings over typical stages of object life cycles is a rewarding exercise with students. Attention to the object's biography can illuminate large-scale or theoretical processes: colonial collecting, for instance, created sharp shifts in meaning in objects as they changed hands and contexts (on object biography see also Joy 2009: 552; Gosden and Marshall 1999; Peers 1999).

Questions students might consider at this stage of the exercise include:

- What is the object's physical condition? How has it changed over time?

- What is the history of the object? How did it get to the museum? How has it changed ownership and been circulated? How have the contexts in which the object has existed changed? Has the object's function changed over time?

- Have the meanings and value of the object changed over time, for instance when changing ownership? Does ignorance, ethnocentrism or racism come into the collector's or museum's understanding of the object? How has the museum addressed this in the records? Has the object been identified with input from its community (or communities) of origin, or by collectors who imposed different cultural regimes of value?

- What does it mean now, and to whom?

- What relationships have been involved across the object's biography?

Step 6: Museum Interpretation: As part of a longer project, students could be guided to readings that enable them to develop a sense of genres of objects, regional/cultural/period-specific styles of decoration, and the ways that scholarship about such objects has developed over time. Understanding how objects have been exhibited, and how they might be exhibited (whose authority or voice might be included, how exhibition process and technology affect meaning or reflect power) is also key to a deeper understanding of the shifting meanings of objects and the sociality and power relations of their making and biographies. 


\section{Conclusion: Organising a Session}

For instructors who wish to incorporate object-based learning into core teaching, it is worth noting that university museums make their collections accessible for teaching. Museum databases can vary in the amount of object metadata available online, but if there are reasonable associated records it is a good place to begin thinking about possible connections between course topics and objects. Museum staff can assist instructors to identify the most suitable items for learning sessions on particular topics. Planning ahead is essential: most museums require at least a month's advance notice for working with items from collections store. Handling may be restricted if objects are fragile or culturally sensitive.

Groups working with museum objects are usually required to be small (no larger than 10-15 persons) for security purposes and to ensure careful handling. Larger classes can be divided into two groups which cycle through gallery and study room environments during a session. A guided exercise that contrasts close observation of items on gallery display (inside cases) and items in the research space (outside of cases) can provide a memorable learning experience. However, we have noted repeatedly that the experience of working directly with historic objects stimulates responses that do not (and cannot) occur when the same object is being viewed behind glass. To maintain the study value of that experience, and given the logistical challenges for museum staff to satisfy repeated follow-on requests for access to objects, students should be encouraged to create for themselves a digital set of supplementary records for ongoing study and reflection. This can be generated through student images taken with phones and high resolution $2 \mathrm{D}$ and $3 \mathrm{D}$ professional images shared by museum staff where available as well as shared documents, drawings and notes.

\section{References:}

Andrews, D., S. Carter, E. Chung, E. Garvey, S. Wajda, C. Whalen, (2014), 'Twenty Questions to Ask an Object', Retrieved 15 May 2019 from: https://networks.h-net.org/twenty-questions-ask-object-handout.

Bohaker, H., Corbiere, A.O. and Phillips, R.B. (2015), 'Wampum Unites Us: Digital Access, Interdisciplinarity and Indigenous Knowledge: Situating the GRASAC Knowledge Sharing Database', in R. Silverman (ed), Museums as Process: Translating Local and Global Knowledges, London: Routledge, pp. 45-66.

Brooks, M., (2004), English Embroideries of the Sixteenth and Seventeenth Centuries in the collection of the Ashmolean Museum, Ashmolean Handbooks, London: Jonathan Horne.

Chatterjee, H. J. (2010), 'Object-based learning in higher education: The pedagogical power of museums', University Museums and Collections Journal, 3: 179-181.

Chatterjee H.J. and Hannan L., (2015), Engaging the Senses: Object-Based Learning in Higher Education, London: Routledge.

Duhs, R. (2010), 'Learning from university museums and collections in higher education: University College London (UCL)', University Museums and Collections Journal, 3: 183-186.

German, S. and Harris J. (2017), 'Agile Objects', Journal of Museum Education, 42(3): 248-257.

Gosden, C. and Marshall, Y. (1999), 'The cultural biography of objects', World archaeology 31(2): 169-178.

Hannan, L., Chatterjee, H. and Duhs, R. (2013), 'Object Based Learning: A powerful pedagogy for higher education', in A. Boddington, J. Boys and C. Speight (eds), Museums and Higher Education Working Together: Challenges and Opportunities, Farnham, UK: Ashgate, pp. 159-168

Joy, J. (2009) 'Reinvigorating Object Biography: Reproducing the Drama of object Lives', World Archaeology, 41(4): 540-556. 
Kopytoff, I. (1986), 'The Cultural Biography of Things: Commoditization as a Process', in I. Kopytoff and A. Appadurai (eds), The Social Life of Things: Commodities in Social Perspective, Cambridge: Cambridge University Press, pp. 64-94.

Miller, P. (2013), Cultural Histories of the Material World, Ann Arbor: University of Michigan Press.

Penn State guide for Instructors, Object Biography, Retrieved 7 June 2019 from: https://www.penn.museum/teachers-and-students/for-penn-instructors/sample-lessons-and-activities.

Parker, R. (2012), The Subversive Stitch: Embroidery and the Making of the Feminine, London: I.B. Tauris.

Peers, L. (1999), 'Many tender ties': The shifting contexts and meanings of the S BLACK bag', World Archaeology, 31(2): 288-302.

Prown, J.D. (1982), 'Mind in Matter: An Introduction to Material Culture Theory and Method', Winterthur Portfolio 17(1): 1-19.

Racette, S.F. (2005), 'Connecting Sources and Re-contextualizing Material Culture: Taking Another Look at Hide Coats,' Unpublished paper presented at the Museum Ethnographers Group Conference, Manchester, UK, May 9-10, 2005.

Riello, G. (2017), 'Things that shape history: material culture and historical narratives', in K. Harvey (ed), History and Material Culture: a student's guide to approaching alternative sources, London: Routledge, pp. 27-50.

Romanek, D. and Lynch, B. (2008), 'Touch and the value of object handling: Final conclusions for a new sensory museology', in H.J. Chatterjee (ed), Touch in museums: Policy and practice in object handling, Oxford: Berg, pp. 275-286.

Rose, G. and D. Tolia-Kelly (eds) (2012), Visuality/Materiality: Images, Objects and Practices, Farnham: Ashgate.

Ulrich, L.T., Gaskell, I., Schechner, S. and Carter, S.A. (2015), Tangible Things: Making History Through Objects, New York: Oxford University Press.

Van Kirk, S. (1999), Many Tender Ties: Women in Fur-Trade Society, 1670-1870, Winnipeg: Watson \& Dwyer.

Vitelli, G. (2014), 'Thinking with Objects: The Ashmolean Museum's University Engagement Programme in the Oxford Academic Community'. In S.S. Jandl and M.S. Gold (eds), A Handbook for Academic Museums, Vol.3, Cambridge, MA: MuseumsEtc., pp. 44-61.

Vitelli G. (2015), 'One Object, Many Meanings: Narratives in the University Museum', in L. Meijer-van Mensch and A. MacDevitt (eds), ICOM Museum International: Museum Collections make Connections, Vol. 65: pp. 257-260.

Woodward, S. (2016), 'Object interviews, material imaginings and 'unsettling' methods: interdisciplinary approaches to understanding materials and material culture', Qualitative Research, 16(4): 359-374.

\section{Notes:}

\footnotetext{
${ }^{1}$ For an example of a multi-disciplinary team research approach using object encounters, see: http://objectlives.com/discovery-process (Retrieved 26 May 2019).
} 